\title{
A gestão sistêmica da educação: do âmbito nacional ao contexto do poder local
}

\section{Edson Francisco de Andrade*}

\section{Resumo}

Este artigo aborda o movimento recente de criação de sistemas próprios na gestáo da educação Nacional, Estadual e Municipal. O texto está subdividido em três partes. Dessa forma, é analisado primeiramente o significado histórico-etimológico de sistema, assim como as nuances que envolvem sua incorporaçáo ao campo educacional. A segunda parte aborda a interface entre a perspectiva de gestáo sistêmica e os fundamentos do Estado federativo brasileiro. Por último, discute-se a relação entre a opção pela criação do sistema de educação no Município e a viabilização da autonomia Municipal para gestar sua Política Educacional. Nas conclusóes é realçada a necessidade de construçáo do Sistema Nacional de Educação como mecanismo articulador da Política Nacional de Educação, com foco na materialização do Regime de Colaboração com os sistemas estaduais e municipais de educação.

Palavras-chave: Gestão da Educação. Política Nacional de Educação. Regime de Colaboração.

* Doutor em Educação pela Universidade Federal de Pernambuco (UFPE). Professor do Departamento de Administração Escolar e Planejamento Educacional e do Programa de Pós-Graduação em Educação da Universidade Federal de Pernambuco (UFPE). 


\section{Introdução}

O direito da criação de sistemas próprios de educação em e por cada ente de poder federado foi garantido pela Constituição Federal do Brasil de 1988, em seu Art. 211 (BRASIL, 2005), e pelo Art. $8^{\circ}$ da Lei de Diretrizes e Bases da Educação Nacional (LDB), de 1996 (BRASIL, 1996). Recentemente o interesse político-social pela implementação desse preceito legal vem sendo manifesto por segmentos da sociedade civil organizada, envolvidos com o processo de democratização da educação, conforme se observou nas conferências de educação que ocorreram nos âmbitos municipal e estadual (em 2009), na Conferência Nacional de Educação de 2010 (CONAE), mantendo-se o foco temático na CONAE de 2014, intitulada "O PNE na articulação do Sistema Nacional de Educaçáo”. Pode-se considerar que a realização de conferências tem buscado ratificar os fundamentos da gestão democrática (participação social cidadá, autonomia, descentralização, controle social, entre outros), tomando-se por base a gestão sistêmica em todos os âmbitos da administraçáo da educação do País.

A pressuposição que tem prevalecido é de que nesta forma de organização gestionária reside a esperança da superação do paradigma de gestão da educação centrado na figura do gestor, seja da secretaria de educaçáo ou da escola. Esse entendimento nos instiga analisar as razóes pelas quais o modelo de gestão sistêmica vem sendo requerido na atual conjuntura histórica em que os entes federativos são convocados a constituírem seus sistemas próprios de educação. Para tanto, subdividimos a constituição do corpus teórico-metodológico deste estudo em três partes, conforme se apresenta na sequência do presente texto. Assim, tematizaremos primeiramente o significado histórico-etimológico de sistema, assim como as nuances que envolvem sua incorporação ao campo educacional.

A segunda parte do texto aborda o fato de que a perspectiva de gestão sistêmica na educação traz consigo a concepção de organização do todo (a educação nacional), ao mesmo tempo em que se faz necessário respeitar a autonomia das partes (a educação no âmbito do poder estadual/local), constituindo, desta feita, uma lógica de ação que se coaduna aos fundamentos do federalismo, visto que as responsabilidades educacionais de cada ente federado (Uniāo, Estados, Distrito Federal e Municípios) obedecem a um ordenamento legal e a uma estrutura administrativa oficial, sem, contudo, prescindir da capacidade de prover os princípios e diretrizes legais da organização e da gestáo das atividades educacionais por cada ente federado.

Por último, discutiremos a relação entre a opção pela criação do sistema municipal de educação e a viabilização da autonomia Municipal e do regime de colaboração com os demais entes federativos. Nesta etapa, ressaltam-se elementos que 
fundamentam a gestáo sistêmica da educação municipal, a saber: incremento das atribuiçôes desenvolvidas pelo Conselho Municipal de Educação (CME); elaboração do Plano Municipal de Educaçáo (PME); e impulsão ao Regime de Colaboração entre os entes federativos quanto ao processo de definiçấo e execução das políticas educacionais.

\section{Concepção de gestão sistêmica e sua contextualização no campo educacional}

A compreensão do campo educacional como conjunto de açóes elaboradas e postas em prática seguindo uma lógica sistêmica tem significados distintos, considerando-se, sobretudo, os diferentes contextos históricos em que se faz menção à educação e ao termo sistema. Conforme observa Sander (1993, p. 341), "os diferentes significados atribuídos ao termo em seus variados empregos indiscriminados revela uma evidente falta de sistematizaçáo a respeito de seu uso no Brasil". O que o autor chama a atenção sobre o emprego indiscriminado do termo sistema, tomando a história republicana da educaçáo nacional como marco temporal, diz respeito à diversidade de contextos e circunstâncias em que o termo é empregado, como, por exemplo, sistema de educação, sistema escolar, sistema universitário, sistema de ensino, sistema de avaliação do ensino, entre outros.

Pode-se considerar que a utilização deste termo com o propósito de referir-se, estritamente, ao processo político-pedagógico em que o ensino escolar deve pautar-se, constitui um fato recente, se comparado à referência aos vários aspectos relacionados à educação com os quais a noção de sistema tem sido empregada. É possível perceber que o uso indistinto do termo, em muitos casos, náo corresponde ao que atualmente se preceitua a respeito da expressão sistema de educação, conforme o disposto no marco legal e na literatura educacional.

Originário da Física, o termo sistema, segundo Agesta (1986), foi introduzido nas Ciências Sociais por Pareto, e difundido por Parsons, como instrumento metodológico para compreender a inter-relaçáo dos diferentes elementos que constituem as unidades da sociedade. Em sua obra, o autor entende por sistema "o conjunto de coisas que ordenadamente entrelaçadas contribuem para determinado fim; trata-se, portanto, de um todo coerente cujos diferentes elementos são interdependentes e constituem uma unidade completa" (AGESTA, 1986, p. 1127).

Cury (2000), respaldando-se no sentido etimológico e histórico, explica que o termo deriva da palavra systêma, que representa uma composição de syn (em latim cum, em português com) acrescida de ístemi (estar ao lado de). Compreende-se, pois, sistema como elementos coexistentes lado a lado e que, convivendo dentro de um mesmo ordenamento, formam um conjunto articulado (CURY, 2000). 
Essa noção abrangente de sistema abre precedente para que o termo apareça relacionado até mesmo aos 210 anos de vigência da educação jesuítica (1549-1759), considerando-se a capacidade de autofinanciamento dos colégios e o exercício da autonomia para decidir sobre sua estrutura curricular, válida para toda a ordem da Companhia de Jesus. Na realidade, no século XIX, a educação ainda não é assumida pelo Estado brasileiro como direito social a ser garantido universalmente aos seus cidadáos. A primeira Constituição Federal, outorgada em 1824, refere-se à educaçáo de forma muito superficial no artigo 179 (BRASIL, 2001a). Tratava-se pontualmente do direito ao acesso à instrução primária, bem como a colégios e universidades para uma pequena fração da população.

A compreensão de sistema de educação que passa a ser incorporada ao campo educacional pressupóe a reuniâo de elementos distintos que, reunidos em torno de objetivos comuns, formam um todo, administrado para um mesmo fim - neste caso, a educação (VASCONCELOS, 2003). Com efeito, o surgimento do sistema educacional apresenta-se como resposta à crescente demanda por um modelo de educação organizado, a partir de um corpo doutrinário, e passível de ser mobilizado face ao objetivo de atingir um determinado fim. Nesse sentido, a expressão "sistema de educaçáo" foi incorporada ao contexto educacional brasileiro como consequência dos movimentos de 1930 em que se reclamava a educaçáo escolar como resposta às novas demandas por qualificaçáo para o trabalho, decorrente das transformaçóes, sobretudo, econômicas que o País experimentava.

É nessa conjuntura que a educação passa a ser requerida em caráter sistêmico, dotada de intençóes que precisavam ser operadas por via de mecanismos que atingissem o País em toda sua amplitude. Um passo importante na direçáo de uma educação sistematizada no Brasil foi a criação do Ministério da Educação e Saúde Pública, em 1931, e, ainda com maior destaque, sua inscrição na Constituição de 1934 (BRASIL, 2001a). É pertinente ressaltar que essa Carta Magna se torna um marco no que concerne à Organização da Educaçăo Nacional, sobretudo, por fundar, em caráter oficial, os sistemas estaduais, assim como o Sistema Federal de Educação. Tal dispositivo legal não faz menção aos sistemas municipais de educação, uma vez que os municípios ascenderam, como ente federado, com autonomia para criar e legislar sobre educação, apenas na Constituição de 1988.

Bordignon (2009), fundamentando-se na concepção de sistema desenvolvida nas Ciências Sociais, propóe princípios que considera fundantes para modelo sistêmico em processo de consolidação no campo educacional, são eles: totalidade, sinergia, intencionalidade, autonomia, organização e normatização. Sobre o princípio de totalidade, entende-se a necessária interdependência/conectividade das partes no todo, 
sem a qual não adquirem significado, "ainda quando situado como subsistema, porque inserido num todo maior, no qual funciona como parte, não perde a dimensão de totalidade no seu âmbito próprio" (BORDIGNON, 2009, p. 25).

Quanto ao princípio da sinergia, compreende-se que as partes, quando articuladas, assumem novo significado no todo pela troca de energia, que gera sinergia e transfere a cada uma a força das demais. Nesse sentido, a força do todo se torna maior do que a soma das forças de suas partes. Já o princípio da intencionalidade constitui a razão do sistema. Nesse caso, a finalidade da gestáo sistêmica é a "energia que liga as partes no todo" (BORDIGNON, 2009, p. 26).

O princípio da autonomia é referido como identidade/capacidade de autorregulação do sistema. A organização estabelece a articulação, as inter-relaçôes das partes no todo, em vista da finalidade comum. A organização das partes no todo estrutura o sistema. Assim, os diferentes enfoques da teoria das organizaçóes convergem para um ponto comum: concebem a organização como um sistema constituído por um conjunto de partes situadas como variáveis mutuamente dependentes. Por último, o princípio da normatização constitui-se elemento essencial para garantir a efetividade dos princípios anteriores. Pode-se conceber que o grau de autonomia de um sistema é determinado por sua intencionalidade e pelas normas que o instituem. Por conseguinte, "a norma geral estabelece limites, mas não subordinação. No espaço dos limites definidos pela norma, o sistema se situa como sujeito dotado de autonomia e organização própria” (BORDIGNON, 2009, p. 28).

É em função desse conjunto de princípios que a implantação do sistema de educação exige a criação e/ou fortalecimento de instâncias de interlocução entre o Estado e a sociedade civil organizada com legitimidade para o planejamento e acompanhamento de políticas para a educação, e com capacidade para viabilizar a colaboração entre as instituiçôes envolvidas com a garantia da educação básica em cada esfera administrativa. Seguindo esse raciocínio, Gandini e Riscal (2007, p. 106) salientam que é possível afirmar a existência de um sistema "quando existem órgãos articulados, responsáveis pela detecção e análise de problemas, estudo de soluçôes e de sua viabilidade técnica e financeira que culminam com a apresentação de programas e projetos educacionais, em todos os níveis de ensino".

A concepção de operacionalização da educação escolar à luz de propósitos estabelecidos previamente adquire concretude com a introdução dos planos de educação que, conforme analisa Saviani (1999), tem origem nas mesmas condições em que se introduz a ideia dos sistemas de educação em nosso país. Este autor destaca que "o Manifesto dos Pioneiros da Educação Nova lança a ideia de plano de educação como um instrumento de introdução da racionalidade na educação visando dar-lhe organicidade, isto é, organizando-a na forma de sistema" (SAVIANI, 1999, p. 133). 
É oportuno ressaltarmos que o entendimento de sistema, como discurso fundante que passa a ser incorporado no campo educacional, denota um conjunto de atividades organizadas sob normas próprias, portanto, autônomas, mas também comuns a todas as suas instâncias. Partindo desse entendimento, Saviani (1999, p. 120), considera que um sistema de educação significa "uma ordenação articulada dos vários elementos necessários à consecução dos objetivos educacionais preconizados para a população à qual se destina. Supóe, portanto, o planejamento".

A relação entre os requisitos de coerência e de intencionalidade que se apresenta como propriedade inerente ao sistema pode ser conferida, especialmente quando da apropriação do termo à educação, a partir da consideração de que até a Lei no 4.024/61 (BRASIL, 1961), a expressão "diretrizes e bases" ainda não integrava o vocabulário dos profissionais da educação, muito menos constituía terminologia preceituada no ordenamento jurídico correspondente à organização da educaçăo brasileira. Acata-se, assim, a hipótese de que o termo sistema surge no cenário da educação brasileira sem que de fato houvesse uma orientação legal que estabelecesse parâmetros em que as açóes neste campo pudessem ser articuladas por meio de mecanismos que garantissem coerência em âmbito nacional.

Conforme análise da legislação que versa sobre a organização da educação em âmbito nacional, considerando-se, sobretudo, a ordem cronológica, a Lei n ${ }^{\circ}$ 5.540/68 (BRASIL, 1968), que dispóe sobre a Reforma Universitária baixada pelo Regime Militar, pode ser considerada a primeira Lei na qual a terminologia sistema de educação é utilizada com relativa constância. Não obstante, a Lei $n^{\circ}$ 5.692/71 é a que melhor emprega a expressáo sistema de educação, mantendo-se coerente no conjunto de seus artigos (BRASIL, 1971).

É, portanto, pertinente reafirmar que o surgimento da lógica de sistema na educação se correlaciona com a manifestação de intencionalidade em relação à ação educativa, mas também com a emergência de um modelo educacional que pressupóe organização sob normas próprias, construídas no coletivo dos indivíduos que compartilham dos processos educativos, ainda que saibamos que este ideário de açáa colegiada não fora exercido plenamente, constituindo, inclusive, uma reivindicação social contemporânea.

A requisição de que a lógica de ação do sistema na educação esteja respaldada pela sua capacidade de dar-se as próprias normas, coaduna-se com o princípio de autonomia que também é creditado ao papel que se espera ser exercido pelos conselhos de educação. Tal requerimento consubstancia-se, por um lado, ao pleito de que o sistema de educação não seja concebido como projeçáo fielmente reproduzida do contexto em que está inserido, o que o reduziria a condição de estrutura (SANDER, 
1993), por outro lado, a reafirmação de que sua consecução corrobore com a constituição da realidade social com que se relaciona. Desse modo, o que se persegue é uma dinâmica na açáo do sistema numa direçáo em que seus sujeitos possam compartilhar a construção da história social no locus onde se materializam os processos educativos.

\section{A gestão sistêmica da educação no âmbito nacional}

É possível afirmar que o discurso sistêmico de gestão tem sido difundido no campo educacional por meio de enunciados que delimitam conceitos e escolhas temáticas assumidas em práticas discursivas desenvolvidas em espaços públicos como as conferências de educação que aconteceram nos municípios e estados (BRASIL, 2009), assim como nas conferências nacionais de educação (BRASIL, 2014), em que se verificou correlações entre os fundamentos da gestão democrática (participação social cidadâ, autonomia, descentralização, controle social, entre outros) e a proposição do sistema nacional de educação.

Também é possível perceber a produção e reprodução desse discurso nos estudos desenvolvidos por pesquisadores da área (FRANÇA, 2009; OLIVEIRA; SANTANA, 2010; BORDIGNON, 2009; WERLE et al., 2008), quando tematizam expectativas para a gestão da educação, sobretudo, correlacionando a relação sistêmica como mecanismo viabilizador de práticas de colaboração entre os poderes federados, quanto à elaboração e execução da Política Educacional em âmbito nacional.

O que é possível apreender dos estudos sobre esse tema é que os principais desafios à consolidação da gestão sistêmica em âmbito nacional têm explicação na própria estrutura federativa adotada no País em que se legitima a autonomia políticoadministrativa dos Estados e Municípios sem uma clara posição quanto ao compartilhamento do poder decisório entre estes entes e a União. Tal quadro impóe limites à efetivaçáo de uma política de Estado para a Educação, concebida e levada a efeito através de permanente relação entre os sistemas de educação instituídos no conjunto dos entes federados.

Conforme tem se apresentado nos estudos (ANDRADE et al., 2009; FRANÇA, 2009), a ausência de um sistema nacional de educação fragiliza a materialização do Regime de Colaboração mediante cumprimento de planos articulados de educação com participação necessária das instâncias de participação. A interpretação desse quadro pelos pesquisadores evidencia a importância da consolidação do Sistema Nacional de Educação (SNE) como espaço público de definição de estratégias para concretização de objetivos coletivos, constituindo-se, portanto, como resposta a uma luta histórica da sociedade e dos educadores brasileiros. 
França (2009, p. 198) chama a atenção para a expectativa de que:

[...] a construção de um SNE, mediante um regime de colaboração, traz concepçóes que devem traduzir a realidade desigual e combinada do Estado brasileiro cujas açóes coletivas - administrativas, pedagógicas, financeiras, jurídicas e de controle social - possam conduzir ao pleno acesso e permanência com qualidade social entre os diferentes níveis e modalidades da educação básica e superior.

Desse modo, a defesa pela construção de um SNE tem por perspectiva a organização e gestão de um projeto nacional de educação, que resguarda a afirmação de organicidade das políticas e de programas, implicando o redimensionamento da atuação dos entes federados, no sentido de que seja possível a garantia de diretrizes educacionais comuns a serem implementadas em todo o território nacional, tendo como perspectiva a superação das desigualdades regionais, e sem prescindir da autonomia de cada esfera de poder, assim como preceitua o federalismo brasileiro. $\mathrm{O}$ modelo sistêmico no âmbito da gestáo da educação nacional assume, assim, o papel de articulador, normatizador, coordenador e, sempre que necessário, financiador dos sistemas de educação (federal, estadual, do Distrito Federal e municipal), garantindo finalidades, diretrizes e estratégias educacionais comuns, mas mantendo as especificidades próprias de cada um (BRASIL, 2009).

Há, portanto, forte apelo em difundir o modelo de gestão sistêmica como estratégia de ação política potencialmente capaz de viabilizar as promessas da Constituição de 1988 quanto ao federalismo cooperativo sob a denominação de regime de colaboração recíproca, conforme dispóem seus artigos 1º, 18, 23, 29, 30 e 211 (BRASIL, 2005). Ocorre que, em face da pendência de regulamentaçáo em lei complementar até hoje inexistente, o regime de colaboração entre sistemas não conhece regulação clara, objetiva, universal e válida para o território nacional.

É importante ressaltar que a omissão do parlamento quanto ao trato dessa matéria não é desprovida de interesse por reeditar relaçóes de mandonismo e de isolamento regional, mantidos sob a obscuridade do que deve ser obrigação dos entes federados quanto à garantia do atendimento às demandas educacionais de forma equânime em todo o País.

Não obstante, as dificuldades para a implantação de um SNE, na atual conjuntura histórica, revelam que a organização de um sistema educacional é tanto a busca de organização pedagógica quanto uma via de jogo de poder (CURY, 2010). Dentre os argumentos que servem às disputas pelo paradigma de gestão que devem 
validar-se no País e que tem se constituído empecilho para a construção do SNE, Cury (2010) destaca a existência de um temor de invasão indébita na autonomia dos entes federativos e, com isso, a eventual perda de autonomia dos mesmos. Conforme explicação do autor,

Após 164 anos de descentralização, há o medo de uma centralizaçáo por parte do Estado Federal enquanto Estado Nacional. Há o receio, por parte do segmento privado na educação escolar, de se ferir a liberdade de ensino e não falta quem assinale o perigo do monopólio estatal. E há também medo da parte da própria Uniáo quanto a uma presença mais efetiva, sobretudo no que se refere ao financiamento da educação básica. (CURY, 2010, p. 28).

A análise de Cury (2010), emblemática para o conjunto dos estudos que tematizam os limites e dificuldades para a formalização de um SNE no Brasil, demonstra que, apesar de inscritos na mesma formação discursiva, a gestão sistêmica da educação e a efetivação de políticas para a educação por meio da colaboração intergovernamental ainda enfrentam resistências nas práticas discursivas que afirmam a vinculação intrínseca entre o entendimento de sistema de educação e a materialização do regime de colaboraçáo, mas que disputam projetos diferentes quanto à consolidação dessa associação nas práticas cotidianas das esferas administrativas. A questão que parece ser transversal aos estudos diz respeito às dificuldades de se garantir o princípio do federalismo cooperativo ao mesmo tempo em que se busca reconhecer o fortalecimento da autonomia de cada nível de poder federado com a criação de seu sistema próprio de educação.

\section{A gestão sistêmica no contexto do poder local}

Cabe menção inicial ao fato de que o surgimento do Sistema Municipal de Educação (SME) aparece numa conjuntura em que o município ganha força e autonomia do ponto de vista geopolítico. Portanto, o SME apesar de ter sido engendrado em conjunto com a criação dos demais espaços de participação, é somente no momento em que o Município ascende ao nível de ente federado autônomo que o ideário de sistema passa a ser extensivo, em condiçóes de se atingir sua concretude, ao âmbito Municipal, assim como preconiza a Constituiçáo Federal de 1988, especificamente, na Seção I, do Capítulo III, Título VIII (BRASIL, 2005). 
Conforme observa Werle et al. (2008, p. 84, grifo nosso):

[...] o que caracteriza um município que assume a responsabilidade pela educação criando o SME é a existência de uma proposta pedagógica ou o esforço de empreender, construir um projeto de educaçáo. É a crença de que é possível articular a educaçáo para além da instabilidade de governos, de que é possível e necessário superar procedimentos burocráticos e mecanicistas, que esvaziam o significado humano, político, pedagógico e gratificante do esforço educativo.

A afirmação política dos municípios brasileiros - enquanto ente federado legitimamente revestido de poder para "empreender, construir um projeto de educação" - é mais bem explicitada através da Lei de Diretrizes e Bases da Educação, no 9.394/96 (BRASIL, 1996). Nesse contexto, inscreve-se, formalmente, o pressuposto da não-subordinação entre um sistema e o outro (Federal, DF, Estadual e Municipal). Funda-se, a partir deste dispositivo legal, a garantia para que cada ente federado possa estabelecer suas próprias estratégias para o atendimento das demandas educacionais. Nesse sentido, é pertinente a consideração de Vasconcelos (2003, p. 112) de que:

[...] os sistemas constituem-se como organizaçóes independentes e autônomas, cujas regulamentaçôes e normas são previstas por seus próprios órgãos normativos, os Conselhos de Educação, que devem considerar, em suas deliberaçóes, o disposto na LDB, no Plano Nacional de Educação (PNE) e nas Diretrizes Nacionais, podendo, entretanto, sem descumprir a lei, organizar-se da forma mais adequada à sua realidade.

Assim, a LDB (BRASIL, 1996) estabelece caracterização para os âmbitos em que os sistemas serão organizados (Federal, Estadual e Municipal), além de reconhecer o papel dos sistemas de educação como mecanismo para assegurar às unidades escolares públicas de educação básica, em cada âmbito administrativo, progressivos graus de autonomia pedagógica e administrativa e de gestão financeira (Art. 15). A análise das competências dos sistemas de educaçáo remete à questão da autonomia das unidades federadas e da intercomplementaridade, pelo regime de colaboração, no exercício das funçôes do Estado, correlação que como tratamos no tópico anterior tem constituído entrave à consolidação do SNE.

O fato da Constituição Federal (1988) conceber a coexistência de sistemas de educação como atributo inerente à própria lógica federativa do País respalda o argumento de que a relação entre os sistemas passa a ser de cooperação, não de 
subordinação, não havendo hierarquia entre eles, assim como não há, constitucionalmente, hierarquia entre as unidades federadas, dotadas de autonomia. Uma vez instituído formalmente o Sistema Municipal, o município se subordina tão somente às leis e diretrizes nacionais e passa a atuar em regime de colaboração, não mais de subordinação, com o estado (BORDIGNON, 2009).

Quanto ao que se compreende tecnicamente por SME, a LDB especifica que sua abrangência inclui: a) as instituições do ensino fundamental, médio e de educação infantil mantidas pelo Poder Público municipal; b) as instituiçóes de educação infantil, criadas e mantidas pela iniciativa privada; e c) os órgãos municipais de educação (BRASIL, 1996, Art. 18).

Não obstante, o espectro político que o SME se insere contempla dimensôes concernentes aos mecanismos de operaçáo dos objetivos que justificam o caráter de intencionalidade e de ação articulada que apontamos enquanto tratávamos das exigências para a implementação do modelo sistêmico. Nesse sentido, o papel a ser desenvolvido pelos órgãos que compóem o sistema de educação tem por perspectiva a proposição de açôes estratégicas com vistas ao desenvolvimento das condiçôes em que as práticas educativas são realizadas nas unidades de ensino.

Desta feita, o significado da criação do SME é de que ele passa a definir a organização formal/legal do conjunto das açóes educacionais no âmbito do Poder Local. A manifestação dessa opção tem sido considerada pelos pesquisadores como sendo mais efetiva quando é procedida por meio de lei municipal, porque explicita e afirma o espaço da autonomia do município e as responsabilidades educacionais próprias, eximindo, por consequência, o sistema estadual de suas responsabilidades quanto à intervenção direta no ente Municipal, salvo quando em atendimento ao que é preconizado pela Constituição.

Esse entendimento é corroborado por Bordignon (2009) quando explicita as razóes que levam a entender o sistema como afirmação de princípios e valores mais permanentes na construçấo da cidadania e da sociedade que se deseja no projeto municipal de educação. Segundo o autor, "ao assumir, com autonomia, a responsabilidade de suas atribuiçóes prioritárias, o município possibilita a dimensáo concreta do exercício do poder local, da cidadania ativa" (BORDIGNON, 2009, p. $38)$.

Faz-se, portanto, necessário considerar que a opção pela criação do SME, com finalidade de ordenação articulada dos vários elementos necessários à consecução dos objetivos educacionais preconizados para o Município exige ajustes importantes no que se refere à atuação dos órgãos legitimamente instituídos na estrutura organizacional desse nível administrativo da federação. Sobre esta matéria, é pertinente considerarmos 
a assertiva de Gandini e Riscal (2007, p. 106), quando fazem menção às atribuições das instâncias co-gestoras do sistema de educação, ressaltando incumbência, como:

[...] recensear e categorizar os elementos que compóe a rede de unidades, analisar dados visando ao aprimoramento da gestáo pública da educação; elaborar planos de açáo; orientar dirigentes educacionais na formulaçáo de normas e no estabelecimento de padróes a serem adotados nos espaços educacionais; propor critérios para o provimento de cargos e transferência de pessoal; propor critérios de distribuição de recursos entre as diferentes unidades administrativas e escolares em articulação com os outros órgãos competentes do governo; estabelecer mecanismos para a valorização dos servidores da educação, docentes e não-docentes, em todos os níveis de ensino.

O que se busca pôr em relevo quando se trata da dimensão política do sistema é a especificidade com que cada um dos entes federados mobiliza suas forças com o propósito de atender as demandas por políticas educacionais nos diversos âmbitos de prioridade. A esse respeito, merece nota o reconhecimento de que a perspectiva de ação articulada no âmbito do SME reclama a consecução do plano educacional, assim como a criação de mecanismos que desenvolvam o acompanhamento de sua implantação no contorno da educação municipal.

Faz-se oportuno destacar que a elaboração do plano educacional, bem como das atribuiçôes que cabem às instâncias de participação na gestão da educação, vinculam-se ao caráter peculiar em que cada sistema de educação municipal é organizado. Conforme nos esclarece Saviani (1999, p. 132-133), as principais providências para a implantação do SME são: verificar a eventual necessidade de ajustes na Lei Orgânica do Município; elaborar um projeto de lei do sistema de ensino do município a ser aprovado pela Câmara Municipal; organização ou, se já existe, reorganização do Conselho Municipal de Educação, de acordo com o disposto na Lei do Sistema de Ensino Municipal; e dar ciência dessas iniciativas à Secretaria Estadual de Educação e ao Conselho Estadual de Educação.

Com efeito, as exigências interpostas aos municípios em face de sua opção pela criação de seu sistema próprio de educação têm provocado ajustes significativos na gestão da educação no âmbito do poder local e, por conseguinte, passaram a constituir objetos de estudo de pesquisadores da área, com destaque para temas como: o processo de ajuste da legislação educacional nos municípios com vistas à reorganizaçáo da educação nacional preconizada pelo novo Marco Legal; os desafios da criação de sistemas, conselhos e planos educacionais no âmbito do Poder Local; além dos entraves ao exercício da colaboração entre os entes de poder federado. 
O ajuste na legislação municipal, em conformidade com a lógica sistêmica de gestão da educação, tem por perspectiva o redirecionamento do papel a ser exercido pelas instâncias de participação legitimamente instituídas no âmbito do poder local, com foco na construção e/ou fortalecimento de mecanismos de mediaçáo dos interesses de vários sujeitos sociais no processo de definição das políticas educacionais (ROSAR, 2005; SAVIANI, 1999). A prática discursiva que tem dado realce a esta matéria apresenta a elaboração da Lei do SME como instrumento de sistematizaçáo de normas que deverão organizar o espaço social de lutas que são empreendidas em função dos diferentes projetos que buscam sua afirmação no campo educacional.

Estudos desenvolvidos sobre o tema (GANDINI; RISCAL, 2007; VASCONCELOS, 2003; WERLE et al., 2008) mostram que a expectativa de funcionamento do sistema de educação reclama, necessariamente, a organização ou, se já existe, reorganização do Conselho Municipal de Educação. É pertinente considerar que o enunciado que difunde a criação do SME como opção que assegura ao município o direito de exercício da autonomia para produzir suas diretrizes educacionais, inscreve-se na mesma formação discursiva que elege o CME como instância responsável por intermediar o processo de detecção e análise de problemas e como legitimidade para a elaboração e acompanhamento da Política Educacional do Município para além da instabilidade de governos (WERLE et al., 2008), além de se constituir mecanismo de viabilização da descentralização do poder decisório entre as instâncias de participação, na perspectiva de interferir na realidade social, operando meios que promovam sua transformação (SANDER, 1993).

\section{O papel do CME a partir do advento de implantação do SME}

O principal impacto da instituição do SME para o Conselho Municipal de Educação (CME) diz respeito ao caráter em que seu papel passa a ser requerido, enfatizando-se sua relevância para o exercício da autonomia do ente municipal quanto à definição de suas diretrizes educacionais. Ao fazer mençáo a este fato, Monlevade (2004) destaca as implicaçóes do novo papel do CME no processo de implantação ou execução das estratégias e ações do Plano Municipal de Educação. Para o autor,

[...] a ação do CME dependerá de seu caráter: sendo o Município cabeça do sistema de ensino, o CME será normatizador, além de órgáo de consulta e assessoria; não o sendo, as normas estarão dadas pelo Conselho Estadual, cabendo ao CME interpretá-las na função consultiva junto à Secretaria Municipal de Educação. (MONLEVADE, 2004, p. 42). 
A atenção que se emprega a incumbência do CME em normatizar sobre as metas e açóes do poder local no âmbito da educação realça o papel desta instância como porta-voz da sociedade civil nos espaços de poder decisório. Considerando alguns estudos de casos que direta ou indiretamente tomam os conselhos municipais de educação como alvo de análises, é possível afirmar que determinados trabalhos vêm evidenciando a importância desses Conselhos não apenas como órgáos normativos e deliberativos dos sistemas municipais de educação (funções técnicas e políticas), mas, sobretudo, como instâncias que, potencialmente, favorecem a consolidação de um processo de municipalização assentado em bases democráticas de gestão, seja em virtude das oportunidades de participação local, seja em decorrência da garantia de transparência e fundamentação das decisóes do executivo municipal (SOUZA; FARIA, 2004).

Outras pesquisas vêm desvelando aspectos concernentes a eventuais disfunções, dificuldades e limitaçôes dos conselhos municipais de educação. Ribeiro (2000) e Meira (2001) chamam a atenção para o fato de que, apesar desses conselhos se fazerem institucionalmente presentes nos municípios estudados, não vêm cumprindo com suas atribuiçóes devido, muitas vezes, ao desconhecimento por parte dos conselheiros não só das suas funçôes, como daquelas referentes ao órgão em questão. Vasconcelos (2003) considera que os conselhos apesar de serem enfaticamente citados como alicerces de sustentação da gestão democrática da educação, da forma como estão constituídos muitas vezes não exercem nem mesmo o papel basilar a eles destinado - o de órgáos consultivos para a implementação de políticas municipais de educação.

Em face dessa realidade, a constituiçáo do CME pode significar um viés de "descentralização" correspondente a uma possibilidade de aumentar a participação não dos indivíduos em geral, mas de determinados indivíduos e grupos. Conforme observa Rosar (2005, p. 113), "para certas conjunturas pode ocorrer o deslocamento do poder do governo central para os governos locais que permita garantir a hegemonia dos grupos que detêm o seu controle". O que procuramos realçar aqui é a relação entre a dinâmica de composição do quadro de conselheiros e as implicaçôes na qualidade de atuação do CME. Sobre este aspecto, faz-se oportuno considerarmos que o conselheiro que exerce o cargo de presidente estabelece a pauta das reunióes, por conseguinte, tem maior poder de influência sobre a agenda de discussôes a ser apreciada pelo coletivo, além das consequências de suas opçóes no momento de coordenar o ritual das intervençôes, podendo interditar ou enfatizar determinados turnos da comunicaçáo em consonância com suas vinculaçôes político-ideológicas (GOMES; ANDRADE, 2009).

No momento atual da vida democrática, os conselhos de educação são convocados a estabelecer relaçôes com os demais conselhos de direitos, tecendo redes 
abrangentes de gestão e monitoramento das diversas políticas públicas. Conforme ponderam Rezende, Soares e Martins (2009), constata-se a preocupação de vincular "o direito à educação" e "os demais direitos" ao empoderamento da população. Esta, ao se fazer valer, "dá visibilidade às demandas por igualdade, exigindo o cumprimento do texto constitucional, na abordagem da concepção, da natureza e da composição de órgáos colegiados, no regime de colaboração, nas atribuiçôes dos conselheiros e nos desafios da gestão democrática" (REZENDE; SOARES; MARTINS, 2009, p. 17).

É também com esse entendimento que Davies (2003, p. 505) considera que a instituição dos conselhos deveria permitir o "movimento de vários segmentos da sociedade no sentido de controlar o Estado e, assim, democratizá-lo, atribuindo a tais conselhos muitas virtudes e poder". Essas prerrogativas elencadas para o conselho e que se coadunam ao cumprimento das funçôes que devem ser exercidas pelo sistema de educação, como o atendimento às demandas educacionais por meio da colaboração entre os entes de poder federado, reclamam um incremento no papel do CME, devendo suscitar o debate sobre quais proposiçôes devem ser elencadas sobre esta matéria, além das estratégias de acompanhamento da ação do Estado no que diz respeito ao entendimento com as demais esferas administrativas.

Cury (2005) salienta a inter-relaçấo entre o fortalecimento dos mecanismos de participação e a materialização do princípio da cooperação entre os três níveis de poder como atributo que se vincula a dimensáo que o papel do CME deve assumir no sistema. Com efeito, esta perspectiva de ação dos conselhos de educaçáo pressupóe a transcendência do exercício de atribuiçôes como emissão de alvará de funcionamento, reconhecimento e/ou credenciamento de instituiçôes educacionais, assim como a realização de sindicâncias, solicitação de esclarecimentos dos responsáveis e formalização de denúncias aos órgãos competentes ao constatar irregularidades. Tais serviços correspondem às funçôes consultiva, normativa e fiscalizadora que certamente constituem parte substantiva de suas prerrogativas de funcionamento, não obstante, devem ser operadas em sinergia com as funçôes propositiva e mobilizadora.

Entendemos que o exercício da função propositiva pelos conselhos de educação exige, necessariamente, a conjugação de critérios como conhecimento técnico e representatividade social, por pressupormos sua inferência como recurso potencializador de maior responsabilidade e compromisso coletivo com o atendimento das demandas por políticas de educação, incluindo-se, ainda, maior possibilidade de uma sistemática de avaliaçáo institucional com vista ao encaminhamento de medidas para a promoçấo de melhoria do fluxo e do rendimento escolar.

Quanto à função mobilizadora, o que está em causa é o interesse de instigar o conjunto dos segmentos sociais no acompanhamento dos serviços educacionais, 
presumindo-se, para tanto, a reuniáo de esforços, tanto por parte do executivo quanto por parte da sociedade civil organizada. Desta feita, há de se convir que a mobilização perpassa o empreendimento de articulaçóes entre os pares que possuem assento no conselho. Nesse aspecto, o que se pretende não é apenas a postura altiva dos sujeitos em exigir maior agilidade dos órgãos gestores quanto à apresentação de respostas às requisiçóes sociais para o campo educacional, mas, sobretudo, maior mobilizaçáo dos próprios sujeitos que exercem a representação, face ao atual quadro em que se constata considerável dissociação entre a voz do representante e os anseios dos representados.

Assim como o fortalecimento e a institucionalização da participação da sociedade civil através do CME, o processo de definição das políticas educacionais do Município assume expectativas que se inserem no campo discursivo da gestão sistêmica, em que evidencia a elaboração de planos municipais de educação, bem como o acompanhamento, fiscalização e avaliação de sua aplicação, matéria que passaremos a abordar no tópico a seguir.

\section{O significado do Plano Educacional na gestão da educação no município}

Assim como tratar da criação de sistemas de educação no âmbito do Poder Local exigiu que contextualizássemos a realidade nacional quanto à perspectiva sistêmica da gestão da educação, a discussão sobre a elaboração e implementação do Plano Municipal de Educação (PME) reclama referência ao modo como o País tem sistematizado seu plano educacional. Estudos reportando-se ao marco temporal em que o PNE (BRASIL, 2001b) entrou em vigor (DIDONET, 2001; VALENTE; ROMANO, 2002, entre outros) já assinalavam a necessidade de desdobramento do PNE em Planos Estaduais de Educação (PEEs) e PMEs, considerando que o processo de participação em fórum ou em comissóes estaduais e municipais é que poderiam garantir que o PNE não fosse, em exclusivo, um plano da União, mas de toda a sociedade.

Nesse sentido, Valente e Romano (2002), em estudo sobre as várias instâncias e etapas que geraram o PNE (2001), discutem as propostas apresentadas pela sociedade em congressos nacionais de educaçáo e o texto final aprovado pelo Parlamento. Os autores trazem ao debate elementos que demonstram como os interesses imediatos do governo federal, majoritário no Congresso, acabaram desfigurando o projeto originário da sociedade, reduzindo-o a uma carta de intençóes. Os resultados da pesquisa revelam que a luta por um verdadeiro PNE continuou na ordem do dia, exigindo a articulação dos movimentos sociais, o conhecimento detalhado da realidade e a disputa global de propostas e projetos. 
A Constituição Federal de 1988 (BRASIL, 2005), proclamada no bojo do processo de redemocratização do País, preconiza, em seu Artigo 21, inciso IX, que cabe à União elaborar e executar planos nacionais regionais de ordenação do território e de desenvolvimento econômico e social. Para o campo educacional, o Art. 214 desta Carta Magna prevê o PNE como instrumento que deve estabelecer as normas gerais para a educaçáo em todo o País, em consonância com o parágrafo único do Art. 23 que requisita a regulamentação de leis complementares para "a cooperação entre União, os Estados, o Distrito Federal e os Municípios, tendo em vista o equilíbrio do desenvolvimento e do bem-estar em âmbito nacional”, indicação ainda não atendida pelo parlamento brasileiro (BRASIL, 2005).

A defesa pela elaboração do Plano de Educação em nível nacional, estadual e municipal, tem por perspectiva a compatibilizaçáo, por exemplo, da capacidade arrecadadora de cada município, o atendimento da demanda e o papel equalizador das demais esferas da administração pública. Trata-se de um mecanismo de viabilização da cooperação inter-sistemas de educação com o intento de suprir as deficiências locais, regionais e estaduais. É com base nesse entendimento que Oliveira (2005) considera que é através da ideia de Plano que se concebe a educação como uma responsabilidade do Poder Público, em sentido amplo, não importando a esfera sob cuja responsabilidade direta se encontre o atendimento à população. "É através da integração das diferentes esferas da administração pública, embutida na ideia de Plano de Educação que se concebe adequadamente as utopias da escola única, do Sistema Nacional de Educação e, do ponto de vista do aluno, da igualdade de oportunidades" (OLIVEIRA, 2005, p. 191).

Ocorre que, após os dez anos de vigência do PNE (2001/2010), as prioridades elencadas no PNE, quanto à elevação da escolaridade da população, à melhoria da qualidade do ensino em todos os níveis, à redução das desigualdades sociais e regionais no tocante ao acesso e à permanência, com sucesso, na educaçáo pública, e à democratização da gestão da educação pública (BRASIL, 2001b), deveriam ser implementadas através de políticas intergovernamentais, em que as metas gerais para o conjunto da Nação tivessem, necessariamente, desdobramento na elaboração de planos estaduais e municipais de educaçáo.

$\mathrm{Na}$ realidade, as expectativas de colaboraçáo apontadas pelo PNE/2001 como condição para a viabilização dos níveis e modalidades de ensino, por um lado, indicam avanços quanto ao entendimento das responsabilidades comuns aos entes federados com a educação brasileira. Por outro lado, constata-se que os desafios para a efetivação das metas persistem, sobretudo, porque as relaçôes entre as três esferas administrativas ainda são pautadas pelo exercício descendente do poder, manifesto através de decisóes 
impostas pelo nível de governo hierarquicamente mais elevado, ou da simples transferência de encargos, sem que haja a distribuição devida dos meios e recursos necessários.

As expectativas foram renovadas com o atual PNE (2014-2024), sancionado pela Lei Federal no 13.005/2014 (BRASIL, 2014), especialmente no que concerne ao combate às desigualdades quanto à capacidade de atendimento aos níveis e modalidades de ensino entre as esferas administrativas do Brasil, reclamam a consolidação da gestão sistêmica em cada nível de governo, no sentido de reeditar e levar a efeito o aperfeiçoamento do regime de colaboração entre os sistemas de educação. Nesse sentido, há de se convir a urgência de que seja instituído o Sistema nacional de Educação, e, no mesmo grau de importância, a universalização dos sistemas estaduais e municipais de educação, assim como a criação de conselhos municipais de educação e a elaboração de planos estaduais e municipais de educação, em consonância com o PNE (2014-2024) ${ }^{1}$.

Pode-se considerar que o País vive um momento muito oportuno para a efetivação do modelo sistêmico de gestáo da educaçáo. Um fato que conta a favor é que o planejamento e a gestão da educação constituíram-se tema debatido intensamente, durante o ano de 2009, por meio das conferências municipais, intermunicipais e estaduais de educaçáo, tendo culminado com as conferências nacionais de educação em 2010 e 2014.

Cabe reconhecimento especial ao fato de que os eixos discutidos tanto nas préconferências quanto na Conferência Nacional de Educação (CONAE) 2014 realçaram uma preocupaçáo comum entre a sociedade civil organizada e o Estado governista com a efetivaçáo compartilhada das açôes educacionais no País. Por isso, a elaboração de conceitos, diretrizes e estratégias nas etapas municipais e estaduais das conferências tiveram por perspectiva a implementação do novo PNE pari passu à construção do Sistema Nacional Articulado de Educação, resguardando a defesa da autonomia dos entes federados e, sobretudo, indicando elementos que garantam organicidade a Política Nacional de Educação.

Todo esse processo de institucionalização da cultura de planejamento no campo educacional, há muito reivindicado por sujeitos sociais ligados aos vários segmentos comprometidos com a educação no País, ganha já concretude social quando se constata a crescente efetivação de planos educacionais construídos pela sociedade brasileira e aprovados sob a forma de lei no âmbito de alguns estados e municípios da federação.

A perspectiva de ação articulada na gestão da educação municipal tem sido tratada, neste estudo, como propriedade inerente à organizaçáo sistêmica, em que se tem por perspectiva que "as iniciativas governamentais podem se tornar sistêmicas e 
articuladas, portanto, políticas públicas de Estado, e não de sucessivos governos, como histórica e politicamente vem ocorrendo" (DOURADO, 2007, p. 2). Tais atribuições vinculam-se, intrinsecamente, a elaboraçáo do PME, devendo ser concebido à luz dos princípios da gestão democrática.

Nesse sentido, nossa concepção sobre a relevância do plano educacional no âmbito do Poder Local coaduna-se a assertiva desenvolvida por Bordignon (2009, p. 92), segundo a qual:

[...] o plano municipal de educação é o instrumento de gestão para tornar efetiva a cidadania e a sociedade preconizada nas bases e diretrizes do Sistema Municipal de Educação. Quando o município não tem plano fica à mercê de açôes episódicas que, mesmo planejadas caso a caso, representam improvisaçôes. Sem plano municipal não há visão de Estado nas açóes, não há caminho a percorrer, mas apenas passos ao sabor das circunstâncias de cada Governo.

Conforme Werle, (2008, p. 84-85), trata-se de:

[...] uma forma peculiar das forças sociais locais interpretarem e inscreverem-se na educaçáo brasileira, explicitando traços característicos e de identidade próprios, incluindo, e não exclusivamente centrando, a ação na criação de estruturas institucionais, focalizando a educação escolar.

No que se refere à elaboração do PME, Saviani (1999, p.132-133) apresentanos alguns passos básicos que consideramos pertinentes nesta discussão, são eles:

a) Efetuar um diagnóstico das necessidades educacionais a serem atendidas pelo Sistema de Ensino Municipal; b) Explicitar as diretrizes que orientaráo a elaboração do plano; c) Definir as metas a serem alcançadas distribuindo-as num cronograma; d) Especificar, para cada setor e respectivas metas, os meios disponíveis e aqueles que deverão ser providos; e e) Elaborar um quadro claro dos recursos financeiros disponíveis assim como das fontes de recursos adicionais de modo a assegurar a viabilidade das metas e ações planejadas.

O primeiro momento do processo apresentado pelo autor, concernente ao diagnóstico das principais demandas educacionais numa determinada municipalidade diz respeito à observância daquilo que preconiza o marco legal quanto aos níveis de 
ensino sob responsabilidade prioritária do Poder Local (Ensino Fundamental e Educação Infantil), avançando-se, progressivamente, na busca pelo atendimento de modalidades consideradas relevantes no espectro da educação básica, como a Educação Especial, a Alfabetização e Educação de Jovens e Adultos e o Ensino Médio. Ressalta-se que a oferta dos diferentes níveis e modalidades de ensino tem como premissa o regime de colaboração entre os entes federados, considerando-se as especificidades de cada unidade da federação.

Em relação ao segundo passo, a ênfase é atribuída à exigência de que as diretrizes e bases que nortearão a confecção do plano sejam explicitadas, no sentido de que as opçôes elencadas, assim como as prioridades acatadas pelo coletivo estejam resguardadas sob justificativas plausíveis. Esse elemento coaduna-se com o terceiro passo, quando Saviani (1999) faz menção à definição das metas a serem contempladas num cronograma que correlacione opçóes e prioridades com etapas a serem operadas ao longo do período de vigência do plano. Trata-se de levar a efeito um conjunto de açóes pautadas em intençôes objetivas quanto às exigências diagnosticadas na primeira fase do plano.

$\mathrm{Na}$ sequência, têm-se a preocupação com a definição dos recursos correspondentes às especificidades de cada meta assumida. Este é mais um elemento que deve ser discutido numa perspectiva de cooperação, principalmente, entre o Município e o Estado, sobretudo, quando se refere ao provimento da infraestrutura necessária às atividades inerentes à escolarização, como: a) adequação do número de escolas e de salas de aula ao quantitativo de alunos, de acordo com as exigências de cada nível e modalidade da educação; b) disponibilização de material didático em conformidade com as necessidades de cada etapa da educação; e c) contratação de profissionais da educação e garantia de formação continuada, respeitando-se a área e/ou setor de atuação (professores, pessoal de apoio como secretários de escola, serventes, merendeiras etc.).

Pode-se afirmar que o processo que envolve a elaboração do Plano Municipal de Educação (desde a diagnose até a apresentação do cronograma e orçamento financeiro) reforça tanto a exigência de intencionalidade e coerência quanto a correlação entre prioridades e capacidade de resposta às demandas educacionais e a necessidade de colaboração entre os entes federativos no que concerne à gestão do sistema de educação, uma vez que se faz necessário cumprir as prerrogativas dispostas na organização da educaçáo nacional, buscando, sobretudo, a garantia do acesso e permanência dos alunos em todos os níveis e modalidades da educação básica² ${ }^{2}$ É, sobretudo, por essa razão que o caráter sistêmico na gestão da educação pressupóe não somente a mera 
divisão de responsabilidades, mas também o acompanhamento do cumprimento das atividades de competência de cada esfera de poder, através da participação dos sujeitos sociais que compartilham dos processos educativos.

\section{Considerações finais}

O presente texto tematizou o processo de incorporação do paradigma sistêmico no campo da gestão da educação, ressaltando potencialidades desta perspectiva gestionária no que concerne à viabilização da autonomia e efetivação do regime de colaboração com os demais entes federativos. Compreende-se que a opçãoo pela criação de sistemas próprios de educaçăo (Nacional, Estaduais e Municipais) consubstancia-se a luta pela democratização da gestão da educação pública que vem sendo historicamente requerida nos três entes de poder. Cabe, no entanto, ressaltar que a própria estrutura federativa adotada no País, em que se legitima a autonomia políticoadministrativa dos Estados e Municípios sem uma clara posiçáo quanto ao compartilhamento do poder decisório entre estes entes e a União, constitui principal entrave para a consolidação dessa forma de gestão.

Com efeito, o reconhecimento do significado do sistema próprio de educação como afirmação da autonomia do Poder Local para propor e executar a Política Municipal de Educação, e também como reconhecimento legal para que a regulação sobre todos os processos educacionais que se desenvolvem no âmbito da esfera local seja feita pelos órgáos do Sistema Municipal de Educaçáo, tanto podem cumprir a expectativa da descentralização gestionária com benefício para a agilização de açóes como a autorização e acompanhamento de escolas municipais e das escolas de nível infantil mantidas pela iniciativa privada e a gestâo de recursos financeiros destinados formalmente à garantia da implementação das políticas elencadas para o setor educacional podem fazer cumprir estas mesmas açóes, sendo que sob a tutela dos interesses do mandonismo local. Esta última colocação incute a possibilidade de atos praticados à revelia do instituído legalmente e que podem ser encobertos pela capa da autonomia conferida pelo sistema e que é vestida pelo gestor da vez.

Diante do exposto, assumir a opção pelo sistema próprio de educação no âmbito do Poder Local como ordenação dos vários elementos necessários à consecução dos objetivos educacionais preconizados para a população à qual se destina (SAVIANI, 1999), requer a reorganização das instâncias de participação, na perspectiva de que o processo de discussão e deliberação das políticas educacionais para o município integre sujeitos vinculados à educaçấo pública municipal em todos os seus setores, fato que demanda nova configuração e perspectiva de atuação do CME. 
O desafio que se constata sobre essa matéria no contexto atual diz respeito à necessidade de construção de um mecanismo de coordenação federativa das açôes que devem ser objeto do Regime de Colaboração sob as prerrogativas sistêmicas, sobretudo a partir do redesenho das responsabilidades com a educação básica que se verificou nas duas últimas décadas, que também coincide com a ascensão dos municípios ao status de ente autônomo. Para tanto, entendemos que a reciprocidade da constituiçáo de normas, de metas e estratégias comuns requer a existência de sistemas de educação no conjunto dos três entes de poder federado.

O fato é que a ausência de um Sistema Nacional de Educação fragiliza a materialização do Regime de Colaboração, especialmente, no tocante ao cumprimento de planos articulados de educação com participação necessária das instâncias de participação. Desta feita, embora tenhamos o princípio da colaboração como recomendação legal para relação intergovernamental no País, fundando, portanto, o marco a partir do qual deverá ser estabelecida a corresponsabilidade entre os Estados, os Municípios e a União, o que se constata é a indefinição do que se faz imprescindível pactuar entre os sistemas de educaçáo com o fim de atingir o atendimento de toda a educação básica, com especial atenção ao âmbito municipal.

Como exemplo desse fato, constatou-se que o conjunto das prioridades elencadas no PNE (2001-2010), quanto ao acesso e à permanência a escola pública e, sobretudo, à melhoria da qualidade do ensino em todos os seus níveis e modalidades, teve implementação reduzida especialmente porque não foi levado a efeito por meio de estratégias e açôes articuladas com os planos estaduais e municipais de educação. Este é o principal gargalo da efetivação das políticas de educação de forma equânime para o País.

Faz-se pertinente advogar que a dinâmica de criação de sistemas de educação no âmbito dos municípios, além de constituir-se instrumento que assegura o direito do Poder Local emitir diretrizes educacionais em colaboração com os demais sistemas, também se constitui base para que o Sistema Nacional de Educação, que deverá ser instituído até junho de 2016 (BRASIL, 2014), cumpra a solicitação dos diversos grupos que o pleiteia de que este se articule com os estados e os municípios, assumindo, genuinamente, a Política Educacional do País, com perspectiva de que as metas do PNE (2014-2024) tenha, na aliança com os entes federados, a mola mestra para sua implementação.

É importante finalizar destacando que se faz necessário a realização de estudos para melhor compreender as práticas cotidianas na gestão da educação municipal nessa nova conjuntura sistêmica da educação em que ainda se verifica a postura da Secretaria de Educação como centro do sistema de educação, em detrimento do papel periférico 
exercido pelas instâncias de participação social, corroborando, portanto, com a manutenção da forma hierarquizada e centralizada de gestão que se evidencia na figura do gestor.

\section{Notas}

${ }^{1}$ Conforme o disposto no Art. 13 da Lei 13.005/2014, que institui o Plano Nacional de Educação que vigorará no País até 2024 (BRASIL, 2014), “o poder público deverá instituir, em lei específica, contados 2 (dois) anos da publicação desta Lei, o Sistema Nacional de Educação, responsável pela articulação entre os sistemas de ensino, em regime de colaboração, para efetivação das diretrizes, metas e estratégias do Plano Nacional de Educação".

${ }^{2}$ Faz-se importante registrar que a Lei no 13.005/2014 (BRASIL, 2014), que sanciona o PNE (2014-2024), estabelece em seu Art. 8o que "os Estados, o Distrito Federal e os Municípios deverão elaborar seus correspondentes planos de educação, ou adequar os planos já aprovados em lei, em consonância com as diretrizes, metas e estratégias previstas neste PNE, no prazo de 1 (um) ano contado da publicação desta Lei”, ou seja, até 25 de junho de 2015.

\section{REFERÊNCIAS}

AGESTA, Luiz S. Sistema Político. In: SILVA, Benedito (Coord.). Dicionário de Ciências Sociais. Rio de Janeiro: FGV, 1986.

ANDRADE, João M. V. et al. O papel dos conselhos para a criação do Sistema Nacional de Educaçáo. In: FRANÇA, Magna (Org.). Sistema Nacional de Educação e o PNE: diálogos e perspectivas. Brasília: Liber Livro/UFRN, 2009.

BORDIGNON, Genuíno. Gestão da Educação no Município: sistema, conselho e plano. São Paulo: Editora do Instituto Paulo Freire, 2009.

BRASIL. Lei n. 4.024, de 20 de dezembro de 1961. Fixa as Diretrizes e Bases da Educação Nacional. Diário Oficial da União, Brasília, 27 dez. 1961.

BRASIL. Lei n. 5.540, de 28 de novembro de 1968. Fixa normas de organizaçáo e funcionamento do ensino superior e sua articulação com a escola média, e dá outras providências. Diário Oficial da União, Brasília, 23 nov. 1968. 
BRASIL. Lei n. 5.692, de 11 de agosto de 1971. Fixa Diretrizes e Bases para o ensino de $1^{\circ}$ e $2^{\circ}$ graus, e da outras providências. Diário Oficial da União, Brasília, 12 ago. 1971.

BRASIL. Lei no 9.394, de 20 de dezembro de 1996. Estabelece as diretrizes e bases da educação nacional. Diário Oficial da União, Brasília, 23 dez 1996.

BRASIL. Coleção Constituiçōes Brasileiras. Brasília: Senado Federal, 2001a.

BRASIL. Lei n. 10.172, de 9 de janeiro de 2001. Aprova o Plano Nacional de Educação e dá outras providências. Diário Oficial da Uniāo, Brasília10 jan. 2001 b.

BRASIL. Constituição da República Federativa do Brasil de 1988. Brasília: Senado Federal, 2005.

BRASIL. Documento Referência: Conferência Nacional de Educação/CONAE 2010. Brasília: MEC, 2009.

BRASIL. Documento Referência: Conferência Nacional de Educação/CONAE 2014. Brasília: MEC, 2014.

BRASIL. Lei n. 13.005, de 25 de junho de 2014. Aprova o Plano Nacional de Educação e dá outras providências. Diário Oficial da União, Brasília, 26 jun. 2014. CURY, Carlos. R. J. Parecer sobre o processo no 23001.000280/2000. Brasília: Conselho Nacional de Educação, 12 nov. 2000.

CURY, Carlos. R. J. Gestão democrática dos sistemas públicos de ensino. In: OLIVEIRA, Maria A. M. (Org.). Gestäo educacional: novos olhares, novas abordagens. Petrópolis, RJ: Vozes, 2005.

CURY, Carlos. R. J. A questão federativa e a educação. In: OLIVEIRA. Romualdo. P.; SANTANA, Wagner (Org.). Educação e Federalismo no Brasil: combater as desigualdades, garantir a diversidade. Brasília: UNESCO, 2010.

DAVIES, Nicholas. Conselhos do FUNDEF: a participação impotente. Ensaio: avaliação, políticas públicas e educacionais. Rio de Janeiro, v. 11, n. 41, p. 502-517, out./ dez. 2003.

DIDONET, Vital. O Plano Nacional de Educação e os planos estaduais e municipais: uma conquista histórica. Gestâo em Rede, Curitiba, n. 33, p. 14-19, nov./dez. 2001. 
DOURADO, Luiz F. Plano Nacional de educação: avaliaçōes e retomada do protagonismo da sociedade civil organizada na luta pela educação. In: FERREIRA, Naura. S. C. (Org.). Políticas públicas e gestão da educação: polêmicas, fundamentos e análises. Brasília: Líber Livro, 2007.

FRANÇA, Magna. Sistema Nacional de Educação: financiamento, valorização dos profissionais da educação básica e perspectivas do PNE (2011-2020) In: FRANÇA, Magna (Org.). Sistema Nacional de Educação e o PNE: diálogos e perspectivas. Brasília: Liber Livro/UFRN, 2009.

GANDINI, Raquel P. C; RISCAL, Sandra A. A constituição do sistema de ensino paulista: das diretorias regionais e serviços de inspeção. Revista Brasileira de Politica e Administração da Educação, Goiânia, v. 23, n. 1, p. 105-120, jan./abr. 2007.

GOMES, Alfredo M; ANDRADE, Edson. F. O discurso da gestão escolar democrática: o conselho escolar em foco. Educação \& Realidade, Porto Alegre, v. 1, p. 83-102, jan./abr. 2009.

GRACINDO, Regina. Os sistemas municipais de ensino e a nova LDB: limites e possibilidades. In: BRZEZINSKI, Iria (Org.). LDB Interpretada: diversos olhares se entrecruzam. 4. ed. São Paulo: Cortez, 2000.

MEIRA, Nelson W. R. Conselhos municipais de educação e a descentralização da gestão educacional na Bahia. Gestão em Rede, Curitiba, PR, n. 32, p. 17-21, out. 2001.

MONLEVADE, João A. A importância do Conselho Municipal de Educação na elaboraçáo, implantação e acompanhamento da execução do PME. In: BRASIL. Ministério da Educação. Programa Nacional de Capacitação de Conselheiros Municipais de Educação: Pró-Conselho. Brasília: MEC, 2004.

OLIVEIRA, Dalila A. Gestão democrática da educação: desafios contemporâneos. 4. ed. Petrópolis, RJ: Vozes, 2005.

OLIVEIRA, Romualdo P.; SANTANA, Wagner. (Org.). Educação e Federalismo no Brasil: combater as desigualdades, garantir a diversidade. Brasília: UNESCO, 2010.

REZENDE, Antônio P; SOARES, Edla; MARTINS, Paulo H. Conselhos de Educação e Direitos Humanos: diálogos da contemporaneidade. Brasília: MEC, 2009. RIBEIRO, Wanderley. Os conselhos municipais de educação na Bahia: descentralização da gestáo educacional? Educação e Contemporaneidade, Salvador, BA, v. 9, n. 13, p. 121-137, jan./jun. 2000. 
ROSAR, Maria de Fátima. Félix. A municipalização como estratégia de descentralização e desconcentração do Sistema Educacional Brasileiro. In: OLIVEIRA, Dalila A. (Org.). Gestão democrática da educação: desafios contemporâneos. 4. ed. Petrópolis, RJ: Vozes, 2005.

SANDER, Benno. Sistemas e anti-sistemas na educação brasileira. Revista Brasileira de Estudos Pedagógicos: Brasília, v. 74, n. 177, p. 335-370, maio/ago. 1993.

SAVIANI, Demerval. Sistemas de ensino e planos de educação: o âmbito dos municípios. Educação e Sociedade, Campinas, v. 20, n. 69, p. 119-136, dez. 1999.

SOUZA, Donaldo B; FARIA, Lia C. M. Reforma do estado, descentralização e municipalização do ensino no Brasil: a gestão política dos sistemas públicos de ensino pós-LDB 9.394/96. Ensaio: avaliação política pública educacional. Rio de Janeiro, v. 12, n. 45, 2004.

VALENTE, Ivan; ROMANO, Roberto. PNE: Plano Nacional de Educação ou carta de intenção? Educação \& Sociedade, Campinas, SP, v. 23, n. 80, p. 96-107, set. 2002.

VASCONCELOS, Vera M. R. Conselhos municipais de educaçáo: criação e implantação em face das novas atribuiçóes dos sistemas de ensino. In: SOUZA, Donaldo B.; FARIA, Lia. C. M. (Org.). Desafios da educação municipal. Rio de Janeiro: DP\&A, 2003.

WERLE, Flávia O. C. et al. O Sistema Municipal de Ensino e suas implicações para a atuação do Conselho Municipal de Educação. Revista Brasileira de Política e Administração da Educação, Goiânia, v. 24, n. 1, p.79-109, jan./abr. 2008. 


\section{A systemic management education: the context of national power local}

\begin{abstract}
This study discusses the recent movement of creating own systems in national, state and municipal education management. The text is divided into three parts. We analyze first the historical and etymological meaning of system as well as the nuances involving their incorporation into the educational field. The second part addresses the interface between the perspective of systemic management and the fundamentals of the Brazilian federal state. Finally, we discuss the relationship between the option for creating the educational system in the Municipality and the feasibility of municipal autonomy to manage its Education Policy. The conclusions highlight the need for construction of the National Education System as a mechanism articulator of the National Policy on Education, with a focus on the materialization of Collaboration Scheme with both state and local systems of education.
\end{abstract}

Keywords: Education management. National education policy. Collaboration scheme.

\section{Una gestión sistémica de educación: del ámbito nacional al contexto del poder local}

\section{Resumen}

Este estudio analiza el reciente movimiento de creación de sistemas propios en la gestión de la educación Nacional, Provincial y Municipal. El texto está dividido en tres partes. Primeramente analizamos el significado histórico y etimológico de sistema como también los matices que implican su incorporación en el ámbito educativo. La segunda parte aborda la relación entre la perspectiva de la gestión sistémica y los fundamentos del estado federal brasileño. Finalmente, se discute la relación entre la opción de crear un sistema de educación en el ámbito municipal y la posibilidad de mantener la autonomía al gestar su política de Educación Municipal. En las conclusiones se destaca la necesidad de la construcción del Sistema Nacional como un mecanismo articulador de la Política Nacional de Educación, con especial atención en la elaboración de un régimen de Colaboración con los sistemas estatales y municipales de educación.

Palabras claves: Gestión de la Educación. Política Nacional de Educación. Régimen de colaboración. 


\section{Edson Francisco de Andrade}

E-mail: edsonprofessor@uol.com.br

Recebido em: 27/12/2013

Aprovado em: 23/6/2014 